\title{
Biological soil crust distribution in Artemisia ordosica communities along a grazing pressure gradient in Mu Us Sandy Land, Northern China
}

\author{
JunHong ZHANG ${ }^{1}$, Bo WU ${ }^{1 *}$, YongHua $\mathrm{LI}^{1}$, WenBin YANG ${ }^{1}$, YaKai LEI ${ }^{2}$, HaiYan HAN ${ }^{1}$, Ji HE ${ }^{1}$ \\ ${ }^{1}$ Institute of Desertification Studies, Chinese Academy of Forestry, Beijing 100091, China; \\ ${ }^{2}$ College of Forestry, Henan Agricultural University, Zhengzhou 450002, China
}

\begin{abstract}
This study investigated the distribution pattern of biological soil crust (BSC) in Artemisia ordosica communities in Mu Us Sandy Land. Three experimental sites were selected according to grazing pressure gradient. In each experimental site, the total vegetation cover, A. ordosica cover, BSC cover, litter-fall cover, BSC degree of fragmentation, BSC thickness and soil properties were investigated in both fixed and semi-fixed sand dunes and simultaneously analyzed in the laboratory. The results showed that at the same grazing pressure, BSC cover and composition were significantly affected by the fixation degree of sand dunes. In addition, BSC cover in the fixed sand dunes was $83.74 \%$ on average, whereas it is proportionally dominated by $28 \%$ mosses, $21 \%$ lichens, and $51 \%$ algae. Meanwhile, BSC cover in the semi-fixed sand dunes was $23.54 \%$ on average, which is proportionally dominated by $6.3 \%$ mosses, $2.5 \%$ lichens, and $91.2 \%$ algae. Fine sand, organic matter, and total nitrogen $(\mathrm{N})$ contents in the fixed sand dunes were all significantly higher than those in the semi-fixed sand dunes. Litter-fall cover decreased along the grazing pressure gradient, whereas BSC fragmentation degree increased. Fine sand content decreased along with the increase of grazing pressure, whereas medium sand content increased in both fixed and semi-fixed dunes. The organic matter and total $\mathrm{N}$ contents in the no grazing site were significantly higher than those in light and normal grazing sites. However, there were no significant differences between the light and normal grazing sites. In addition, there were also no significant differences in BSC thickness between the light and normal grazing sites in the fixed sand dunes. However, a significant decrease was observed in both BSC cover and thickness in the normal grazing site. The BSC in the semi-fixed dunes was more sensitive to disturbance.
\end{abstract}

Keywords: Artemisia ordosica community; biological soil crust; grazing pressure; soil properties; Mu Us Sandy Land

Citation: JunHong ZHANG, Bo WU, YongHua LI, WenBin Yang, YaKai LEI, HaiYan HAN, Ji HE. 2013. Biological soil crust distribution in $A r-$ temisia ordosica communities along a grazing pressure gradient in Mu Us Sandy Land, Northern China. Journal of Arid Land, 5(2): 172-179.

Arid and semi-arid regions of Northern China usually come with sparse vegetation. Nevertheless, the soil surface in the spaces between and under the bunchgrasses, shrubs, and forbs is covered by a community of highly specialized organisms including bacteria, fungi, mosses, lichens, algae, and liverworts, together with soil particles in the first millimeters of the topsoil; these communities are usually called biological soil crusts (BSC) (Eldridge and Green, 1994; Ponzetti and McCune, 2001). As one of the most important bio- logical factors that maintain the stability of soil surface, BSC are essential components of healthy desert ecosystems, and have critical ecological functions in the arid and semi-arid regions (Eldridge and Koen, 1998; Root and McCune, 2012; Yang et al., 2012). Studies of BSC in the arid and semi-arid regions revealed that the major environmental factors influencing BSC distribution are vegetation cover (Maestre and Cortina, 2002; Read et al., 2008), precipitation frequency (Belnap et al., 2004; Büdel et al., 2009),

*Corresponding author: Bo WU (E-mail: wubo@caf.ac.cn) Received 2012-07-19; revised 2012-11-09; accepted 2012-12-16

C Xinjiang Institute of Ecology and Geography, Chinese Academy of Sciences, Science Press and Springer-Verlag Berlin Heidelberg 2013 
topography (Jiao et al., 2008), and disturbance (O’Bryan et al., 2009). Moreover, grazing disturbance reduces both cover and diversity of BSC. Rai et al. (2012) found a marked decline of terricolous lichen diversity in a temperate-alpine shrub and meadow (Garhwal, western Himalaya, India) caused by grazing. Wang et al. (2009) found that over $80 \%$ of the total cover of BSC was destroyed after three years of grazing in the southern part of Gurbantunggut Desert. In addition, the medium sand content of the dune surface soil increased by $13.9 \%$, while fine sand content decreased by $7.4 \%$, and the soil organic matter content decreased by about 50\%. Ponzetti and McCune (2001) found that the livestock-related reductions in the cover and richness of BSC were apparent, which was in contrast with the effects to the vascular plants in a shrub steppe in Oregon, USA.

$\mathrm{Mu}$ Us Sandy Land is an important ecological barrier in Northern China (Han et al., 2012). Artemisia ordosica is the dominant species in the fixed and semi-fixed sand dunes in Mu Us Sandy Land (Zheng et al., 2008; Li et al., 2010a). BSC is commly founded in A. ordosica communities, which appear first under $A$. ordosica shrubs in the semi-fixed sand dunes and grow with increasing plant cover (Zhang et al., 2010; Wu et al., 2012). Grazing resulted in a reduction and fragmentation of the BSC. However, this trend was partially compensated by an increase of newly formed BSC (Hiernaux et al., 1999). Under no grazing condition, the development of BSC in A. ordosica communities is harmful to precipitation infiltration, which will lead to the degradation of $A$. ordosica in the fixed sand dunes (Kobayashi et al., 1995; Li et al., 2007). Although the above-mentioned conclusion lacks enough evidence, the importance of BSC in A. ordosica communities is doubtless.

The main objectives of this study were: (1) to study the BSC cover and composition in A. ordosica communities in the Mu Us Sandy Land, which has received little attention so far; (2) to better understand the ecological effect of BSC in desert environments; and (3) to understand the distribution characteristics of BSC in A. ordosica communities, and the response to grazing disturbance.

\section{Materials and methods}

\subsection{Site description}

Mu Us Sandy Land lies in Northern China, at $37^{\circ} 30^{\prime}-$ $39^{\circ} 20^{\prime} \mathrm{N}$ and $107^{\circ} 20^{\prime}-111^{\circ} 30^{\prime} \mathrm{E}$, being part of the Ordos Plateau. Elevation ranges from 1,000 to 1,500 m, and the total area is about $39,800 \mathrm{~km}^{2}$. Among the twelve sandy zones in China, Mu Us Sandy Land is the only one that lies in the transitional zone from typical steppes to deserts. It has a semi-arid continental climate, and is sensitive to climate and land use changes ( $\mathrm{Wu}$ and $\mathrm{Ci}, 2002)$. The mean annual precipitation is $350 \mathrm{~mm}$, approximately $70 \%$ of which falls between July and September. The annual potential evaporation is $2,300 \mathrm{~mm}$, six times greater than the annual precipitation. The annual mean temperature is around $6.5^{\circ} \mathrm{C}$, with monthly means of $-11.5^{\circ} \mathrm{C}$ in January and $21.8^{\circ} \mathrm{C}$ in July. Prevailing winds are from the northwest in winter, spring, autumn and from the southeast in summer (Zhang et al., 2011). The soil is loose and infertile, and can be classified as aeolian sandy soil, which is very susceptible to wind erosion. A. ordosica is the most important dominant plant species in the study area. BSC is widespread in the $A$. ordosica community, which is an important indicator of the fixation stage of the dunes (Cheng et al., 2004) (Fig. 1). Most of the A. ordosica individuals are middle-aged and elderly in the fixed sand dunes, and the BSC dominated by mosses and lichens is relatively common. However, in the semi-fixed sand dunes the overwhelming majority of the $A$. ordosica individuals are young and middle-aged, and the main crust type is early-development algae crust, with mosses- and lichens-dominating crusts rarely seen (Kobayashi et al., 1995).

\subsection{Experimental design}

Three experimental sites were selected according to grazing pressure during July-September 2011. These sites are Shali $\left(\mathrm{S}_{1}\right.$, no grazing, 2 years after grazing prohibition), Taoli $\left(\mathrm{S}_{2}\right.$, light grazing, $0.5-1$ sheep $\left./ \mathrm{hm}^{2}\right)$, and Wushenzhao $\left(\mathrm{S}_{3}\right.$, normal grazing, 1.5-2 sheep/ $\mathrm{hm}^{2}$ ). In each site, 16 linear plots were selected in both fixed and semi-fixed sand dunes of A. ordosica communities. Each linear plot was $2 \mathrm{~m} \times 50 \mathrm{~m}$, and was divided into 25 quadrats of $2 \mathrm{~m} \times 2 \mathrm{~m}$. Thus, there were 400 quadrats in the fixed dunes and 400 in the semi-fixed dunes in each experimental site, with a total of 2,400 quadrats. In each quadrat, total vegetation cover, A. ordosica cover, BSC cover (mosses, lichens, and algae), litter-fall cover, fragmentation degree, and thickness of BSC were measured. BSC fragmen- 

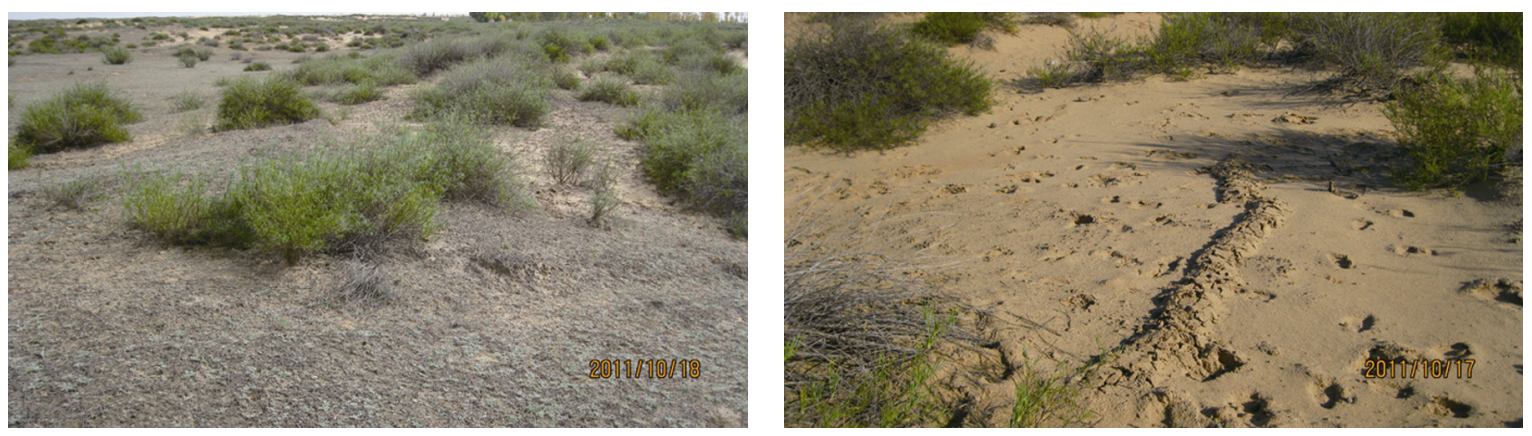

Fig. 1 The A. ordosica communities located in Mu Us Sandy Land; left, A. ordosica community in the fixed dunes; right, $A$. ordosica community in the semi-fixed dunes.

tation degree refers to the BSC area damaged by external forces (mainly grazing) compared with the total BSC area in a single quadrat. The survey method for the maximum and minimum BSC thickness was carried out according to Zhang et al. (2010). Three points were selected to measure the thickness of the BSC in each quadrat, repeated three times at each point, to reduce experimental error. Three quadrats were randomly selected in each linear plot, and the topsoil $(0-5 \mathrm{~cm})$ was sampled in each quadrat, respectively. In total, 288 soil samples were obtained.

\subsection{Laboratory and statistical analyses}

Soil samples were air-dried, and then sieved through a 2-mm mesh; roots and the other debris were removed before the laboratory analysis. Soil particle size was determined via the pipette methods formulated by the Institute of Soil Science, Chinese of Academy of Sciences in a sedimentation cylinder, using sodium hexa-metaphosphate as the dispersing agent (Guo et al., 2008). Soil organic matter content was measured using the dichromate oxidation method of Walkey and Black (Sanmanee and Suwannaoin, 2009), and total nitrogen (N) content was measured using the Kjeldahl procedure (UKD140 Automatic Steam Distilling Unit, Automatic Titroline 96, Italy). Data were analyzed using Windows-based Excel 2007 and SPSS 17.0. BSC and other factor variances in different sites and dune types were analyzed using one-way ANOVA and two-way ANOVA, with post-hoc test. For all the tests, statistically significant differences were assigned to $P<0.05$.

\section{Results}

Total vegetation cover, A. ordosica cover, BSC cover, BSC cover under $A$. ordosica, litter-fall cover, BSC fragmentation degree, and the maximum and minimum thickness of BSC in the fixed sand dunes were significantly higher than those in the semi-fixed sand dunes (Table 1).

\subsection{Vegetation cover and BSC distribution char- acteristics in the fixed dunes of $A$. ordosica communities}

In the fixed dunes, $94.96 \%$ of the total vegetation cover was $A$. ordosica, and the average vegetation cover was $39.13 \%$. No significant differences were observed among the three experimental sites $(P>0.05)$. $\mathrm{S}_{2}$ had the highest BSC cover, followed by $\mathrm{S}_{1}$. $\mathrm{S}_{3}$ had the minimum BSC cover, which was significantly lower than $\mathrm{S}_{1}$ and $\mathrm{S}_{2}$. The average BSC cover in the fixed dunes was $83.74 \%$. The BSC was proportionally dominated by $28 \%$ mosses, $21 \%$ lichens, and $51 \%$ algae crust in the fixed dunes (Table 1). The BSC cover was significantly higher under $A$. ordosica. $\mathrm{S}_{1}$ had the highest litter-fall cover, which was significantly higher than $\mathrm{S}_{2}$ and $\mathrm{S}_{3}$. Significant differences were observed in the BSC fragmentation degree among the three sites, in the following order: $\mathrm{S}_{1}$ $(2.22 \%)<\mathrm{S}_{2}(3.68 \%)<\mathrm{S}_{3}(4.07 \%) . \mathrm{S}_{1}$ had a maximum mean BSC thickness of $8.69 \mathrm{~mm}$, whereas the minimum mean BSC thicknesses in $\mathrm{S}_{1}$ was also higher than in $\mathrm{S}_{2}$ and $\mathrm{S}_{3}$.

\subsection{Vegetation cover and BSC distribution char- acteristics in the semi-fixed dunes with $A$. ordosica communities}

The average vegetation cover in the semi-fixed dunes with $A$. ordosica communities was $14.17 \%$. The vegetation cover in $\mathrm{S}_{1}$ was significantly higher than that in $\mathrm{S}_{2}$ and $\mathrm{S}_{3}$. In the semi-fixed dunes, $96.92 \%$ of the total vegetation cover was $A$. ordosica. $\mathrm{S}_{1}$ had the highest 
JunHong ZHANG et al.: Biological soil crust distribution in Artemisia ordosica communities along a grazing pressure gradient... 175

Table 1 Vegetation cover and BSC distribution in the fixed and semi-fixed dunes with $A$. ordosica communities

\begin{tabular}{|c|c|c|c|c|c|c|c|c|c|c|c|}
\hline \multirow{2}{*}{$\begin{array}{c}\text { Type of } \\
\text { sand dunes }\end{array}$} & \multirow{2}{*}{$\begin{array}{l}\text { Experimental } \\
\text { site }\end{array}$} & \multirow{2}{*}{$\begin{array}{l}\text { Total vegetation } \\
\text { cover }(\%)\end{array}$} & \multirow{2}{*}{$\begin{array}{l}\text { A. ordosica } \\
\text { cover (\%) }\end{array}$} & \multicolumn{3}{|c|}{ Total BSC cover $(\%)$} & \multirow{2}{*}{$\begin{array}{l}\text { BSC cover } \\
\text { under } \\
\text { A. ordosica } \\
(\%)\end{array}$} & \multirow{2}{*}{$\begin{array}{l}\text { Litter-fall } \\
\text { cover }(\%)\end{array}$} & \multirow{2}{*}{$\begin{array}{c}\text { BSC } \\
\text { fragmentation } \\
\text { degree }(\%)\end{array}$} & \multirow{2}{*}{$\begin{array}{c}\text { Max BSC } \\
\text { thickness } \\
(\mathrm{mm})\end{array}$} & \multirow{2}{*}{$\begin{array}{c}\text { Min BSC } \\
\text { thickness } \\
(\mathrm{mm})\end{array}$} \\
\hline & & & & Mosses & Lichens & Algae & & & & & \\
\hline \multirow{3}{*}{$\begin{array}{l}\text { Fixed } \\
\text { dunes }\end{array}$} & $\mathrm{S}_{1}$ & $38.20^{\mathrm{aA}}$ & $37.80^{\mathrm{aA}}$ & $24.84^{\mathrm{aA}}$ & $18.63^{\mathrm{aA}}$ & $45.25^{\mathrm{aA}}$ & $94.50^{\mathrm{aA}}$ & $7.27^{\mathrm{aA}}$ & $2.22^{\mathrm{aA}}$ & $8.69^{\mathrm{aA}}$ & $1.68^{\mathrm{aA}}$ \\
\hline & $\mathrm{S}_{2}$ & $39.90^{\mathrm{aA}}$ & $37.14^{\mathrm{aA}}$ & $24.91^{\mathrm{aA}}$ & $18.69^{\mathrm{aA}}$ & $45.38^{\mathrm{aA}}$ & $93.15^{\mathrm{aA}}$ & $5.28^{\mathrm{cA}}$ & $3.68^{\mathrm{cA}}$ & $7.75^{\mathrm{bA}}$ & $1.40^{\mathrm{bA}}$ \\
\hline & $\mathrm{S}_{3}$ & $40.95^{\mathrm{aA}}$ & $36.57^{\mathrm{aA}}$ & $19.19^{\mathrm{bA}}$ & $14.39^{\mathrm{bA}}$ & $34.95^{\mathrm{bA}}$ & $84.30^{\mathrm{bA}}$ & $3.33^{\mathrm{bA}}$ & $4.07^{\mathrm{bA}}$ & $8.44^{\mathrm{abA}}$ & $1.53^{\mathrm{abA}}$ \\
\hline \multirow{3}{*}{$\begin{array}{l}\text { Semi-fixed } \\
\text { dunes }\end{array}$} & $\mathrm{S}_{1}$ & $18.75^{\mathrm{aB}}$ & $18.28^{\mathrm{aB}}$ & $2.47^{\mathrm{aB}}$ & $0.98^{\mathrm{aB}}$ & $35.76^{\mathrm{aB}}$ & $57.36^{\mathrm{aB}}$ & $2.26^{\mathrm{aB}}$ & $1.24^{\mathrm{aB}}$ & $3.25^{\mathrm{aB}}$ & $0.97^{\mathrm{aB}}$ \\
\hline & $\mathrm{S}_{2}$ & $13.23^{\mathrm{bB}}$ & $12.95^{\mathrm{bB}}$ & $0.97^{\mathrm{bB}}$ & $0.39^{\mathrm{bB}}$ & $14.09^{\mathrm{bB}}$ & $30.77^{\mathrm{bB}}$ & $0.61^{\mathrm{bB}}$ & $2.55^{\mathrm{bB}}$ & $1.35^{\mathrm{bB}}$ & $0.51^{\mathrm{bB}}$ \\
\hline & $\mathrm{S}_{3}$ & $13.20^{\mathrm{bB}}$ & $12.73^{\mathrm{bB}}$ & $1.03^{\mathrm{bB}}$ & $0.41^{\mathrm{bB}}$ & $14.90^{\mathrm{bB}}$ & $33.15^{\mathrm{bB}}$ & $0.75^{\mathrm{bB}}$ & $2.69^{\mathrm{bB}}$ & $1.44^{\mathrm{BB}}$ & $0.53^{\mathrm{bB}}$ \\
\hline
\end{tabular}

Note: $\mathrm{S}_{1}$, no grazing; $\mathrm{S}_{2}$, light grazing; $\mathrm{S}_{3}$, normal grazing. Categories in the same sand dune type with different lower case letters differ significantly at $P<0.05$; categories in the same sites with different upper case letters differ significantly at $P<0.05$.

BSC cover, which was $39.21 \%$, and was significantly higher than $\mathrm{S}_{2}$ and $\mathrm{S}_{3}$. The average BSC cover in the semi-fixed dunes with $A$. ordosica communities was $23.54 \%$. Similar to the fixed dunes, the BSC cover under A. ordosica was significantly higher. The proportion of mosses, lichens, and algae dominated crusts in the semi-fixed dunes with $A$. ordosica communities were $6.3 \%, 2.5 \%$, and $91.2 \%$, respectively. $\mathrm{S}_{1}$ had the highest litter-fall cover, which was significantly higher than $S_{2}$ and $S_{3}$. The BSC fragmentation degree in $S_{1}$ was significantly lower than that in $\mathrm{S}_{2}$ and $\mathrm{S}_{3}$. However, no significant differences were observed in the BSC fragmentation degree between $S_{2}$ and $S_{3} . S_{1}$ had the maximum mean BSC thickness, whereas the minimum mean BSC thickness in $\mathrm{S}_{1}$ was also higher than that in $\mathrm{S}_{2}$ and $\mathrm{S}_{3}$.

\subsection{Physiochemical properties of topsoil in dif- ferent sites and sand dune types}

The topsoil mainly contains three kinds of particles: fine sand $(0-0.05 \mathrm{~mm})$, medium sand $(0.05-0.25 \mathrm{~mm})$ and coarse sand $(>0.25 \mathrm{~mm})$. The weight percentage of fine sand in the fixed sand dunes was significantly higher than that in the semi-fixed dunes in all the three sites. The weight percentage of fine sand decreased with increasing grazing pressure in both the fixed and semi-fixed sand dunes. $S_{1}$ had the highest fine sand content of $31.36 \%$ in fixed dunes. The weight percentage of medium sand increased with increasing grazing pressure in both fixed and semi-fixed sand dunes. $\mathrm{S}_{1}$ had the lowest medium sand content of $33.31 \%$ in fixed dunes. The weight percentage of coarse sand increased with grazing intensity in fixed dunes. However, $\mathrm{S}_{1}$ had the highest coarse sand content of $43.61 \%$ in semi-fixed dunes (Fig. 2).


Fig. 2 Topsoil particle size distribution in different sites and sand dune types 
Further analysis showed that the organic matter and total $\mathrm{N}$ contents of the topsoil were also significantly changed with different sites and sand dune types (Fig. 3). The contents of organic matter and total $\mathrm{N}$ in the fixed dunes were also significantly higher than those in semi-fixed dunes in all the three sites. The organic matter content decreased with increasing grazing pressure in the fixed dunes. However, no significant differences were observed in the organic matter content between $\mathrm{S}_{2}$ and $\mathrm{S}_{3}$ in semi-fixed dunes. The content of total $\mathrm{N}$ for site $\mathrm{S}_{1}$ was significantly higher than those for $S_{2}$ and $S_{3}$ in both the fixed and the semi-fixed sand dunes. However, no significant differences were observed in the content of total $\mathrm{N}$ between $\mathrm{S}_{2}$ and $\mathrm{S}_{3}$.

\subsection{Relationships between BSC cover and the correlation factors in $\boldsymbol{A}$. ordosica communities}

Positive linear relationships exist between BSC cover and total vegetation cover, as well as between $A$. ordosica cover and litter-fall cover in both fixed and semi-fixed dunes with A. ordosica communities (Table 2). Positive linear relationships were also observed be-

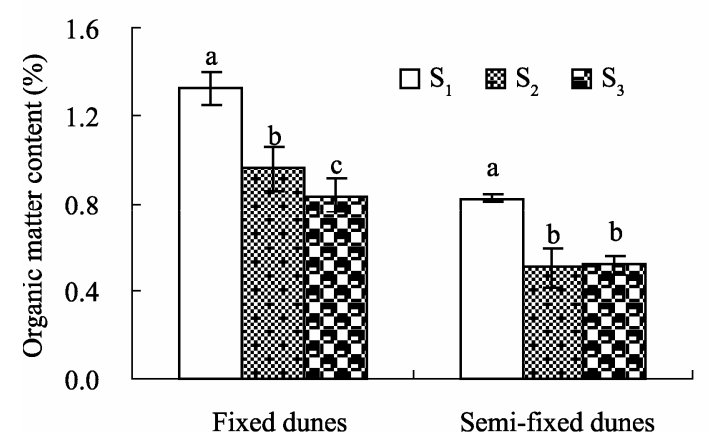

tween litter-fall cover and total vegetation cover in both fixed and semi-fixed dunes. The values of correlation coefficients for the semi-fixed dunes were slightly higher than those for the fixed dunes.

\section{Discussion}

There are no BSC distributed on the shifting dunes in $\mathrm{Mu}$ Us Sandy Land. Shifting dunes slowly changed to semi-fixed dunes as the pioneer plant, A. ordosica, and other settlers appeared. Plants in the semi-fixed dunes can help reducing the near-surface wind speed and wind erosion (Hu et al., 2002). Litter-fall produced by A. ordosica and other plants can enter the soil, and is then decomposed by microorganisms, thereby increasing soil nutrient input (Chen et al., 2009; Maqubela et al., 2009). The contents of organic matter and total $\mathrm{N}$ in the fixed dunes were significantly higher than in the semi-fixed dunes for all the three sites. The more soil nutrient, the more vegetation can be supported by the soil. With the increase of plant cover, the semi-fixed dunes would be established and become fixed dunes. $A$. ordosica is a sparsely-leaved plant species that has

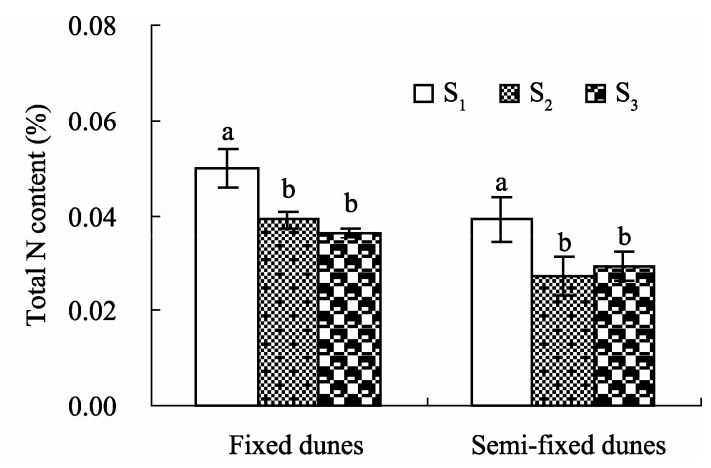

Fig. 3 Topsoil organic matter and total $\mathrm{N}$ contents in different sites and sand dune types

Table 2 Relationship between BSC and upper vegetation in A. ordosica communities

\begin{tabular}{cccccc}
\hline Type of sand dunes & Independent variable $(X)$ & Dependent variable $(Y)$ & Regression equation & $R^{2}$ & $P$ \\
\hline \multirow{3}{*}{ Fixed dunes } & Total vegetation cover & BSC cover & $Y=0.1464 X+77.987$ & 0.0305 & $<0.01$ \\
& A. ordosica cover & BSC cover & $Y=0.2267 X+75.287$ & 0.0744 & $<0.01$ \\
& Litter-fall cover & BSC cover & $Y=0.9690 X+78.135$ & 0.1512 & $<0.01$ \\
& Total vegetation cover & Litter-fall cover & $Y=0.2080 X-2.3916$ & 0.3823 & $<0.01$ \\
\hline \multirow{3}{*}{ Semi-fixed dunes } & Total vegetation cover & BSC cover & $Y=0.8957 X+10.074$ & 0.2105 & $<0.01$ \\
& A. ordosica cover & BSC cover & $Y=0.8955 X+10.446$ & 0.2059 & $<0.01$ \\
& Litter-fall cover & BSC cover & $Y=6.6024 X+15.614$ & 0.3253 & $<0.01$ \\
& Total vegetation cover & Litter-fall cover & $Y=0.1093 X-0.4433$ & 0.4024 & $<0.01$ \\
\hline
\end{tabular}


dense branches close to the ground (Li et al., 2010b; Zhang et al., 2011). Dust from the atmosphere or carried by precipitation can be kept under $A$. ordosica because of the special crown structure of the plant. Thus, fine sand percentage is significantly higher in fixed dunes than in semi-fixed dunes. Our observation is consistent with the results from Guo et al. (2008), who studied BSC development and topsoil properties in the process of dune stabilization at Horqin Sandy Land in Northern China. They found that the thickness of BSC, fine sand, organic matter, and total $\mathrm{N}$ of the topsoil were gradually increased along the dune stabilization gradient. In Mu Us Sandy Land, BSC cover in the semi-fixed dunes was significantly lower than that in fixed dunes, in which more than $90 \%$ of the BSC was dominated by algae, an indicator of the primary stage of the BSC development process. However, about half of the BSC in the fixed dunes were dominated by mosses and lichens. Thus, plant cover, litter-fall cover, and soil properties are important factors that influence the BSC cover and composition (Maestre and Cortina, 2002; Guo et al., 2008; Read et al., 2008; Lan et al., 2012).

BSC is a sensitive indicator of disturbance (Ponzetti and McCune, 2001). In Mu Us Sandy Land, the contents of organic matter, total $\mathrm{N}$, and fine sand in the no grazing site were significantly higher than those in the normal grazing site in both fixed and semi-fixed dunes, whereas BSC fragmentation degree was increased along the grazing pressure gradient. This is consistent with the results from $\mathrm{Xu}$ and Ning (2010). In addition, Wang et al. (2009) also found that BSC cover, organic matter, total $\mathrm{N}$, and fine sand were significantly decreased after three years of grazing in Gurbantunggut Desert. However, in Mu Us Sandy Land, no significant differences were observed in the organic matter content in the semi-fixed dunes of $\mathrm{S}_{2}$ and $\mathrm{S}_{3}$, as well as in the total N content, BSC fragmentation degree, and BSC thickness in both fixed and semi-fixed dunes of $\mathrm{S}_{2}$ and $\mathrm{S}_{3}$. This result demonstrated that intact BSC is more sensitive to grazing. However, Hiernaux (1999) found that BSC fragmentation caused by grazing was partially compensated by an increase of newly formed crusts. Cooper et al. (2001) found that damaged BSC grew more significantly than intact crusts under watery conditions. Thus, an increase in summer precipitation in arid and semi-arid areas would increase the growth rate of fragmented BSC, and may help to ameliorate the damage caused to the crusts by grazing.

The presence of BSC changed the spatiotemporal pattern and re-allocation of soil moisture by decreasing precipitation infiltration, increasing the topsoil water-holding capacity and altering evaporation rates (Li et al., 2010; Xiong et al., 2011). Grazing interference leads to increasing BSC fragmentation, which is favorable for precipitation infiltration (Hiernaux et al., 1999). Finding the ideal grazing intensity is beneficial for the dynamic balance of $A$. ordosica communities in Mu Us Sandy Land.

\section{Conclusions}

Under the same grazing pressure in $\mathrm{Mu}$ Us Sandy Land, the BSC cover and composition were significantly affected by the fixation degree of sand dunes. The total vegetation cover, $A$. ordosica cover, litter-fall cover, BSC cover, and BSC thickness in the fixed dunes were significantly higher than those in the semi-fixed dunes. More than $90 \%$ of the BSC were dominated by algae in the semi-fixed dunes, whereas about $50 \%$ of the BSC in the fixed dunes were dominated by mosses and lichens. The topsoil properties in the fixed dunes were also better than in the semi-fixed dunes. Fine sand, organic matter and total $\mathrm{N}$ contents in the fixed dunes were significantly higher than those in the semi-fixed dunes.

No significant differences were observed in the total vegetation cover and $A$. ordosica cover along the grazing pressure gradient in the fixed dunes. However, litter-fall cover decreased along with the increase of grazing pressure, whereas BSC fragmentation degree increased. No significant differences were observed in BSC cover between the no grazing site $\mathrm{S}_{1}$ and light grazing site $S_{2}$, but the BSC covers of $S_{1}$ and $S_{2}$ were all significantly higher than that of the normal grazing site $\mathrm{S}_{3} . \mathrm{S}_{1}$ had the highest maximum and minimum BSC thickness, whereas $\mathrm{S}_{2}$ had the lowest thickness in the fixed dunes. However, all of the eight variables in Table 1 in the semi-fixed dunes had no significant differences between $S_{2}$ and $S_{3}$, but were all significantly lower than those in $S_{1}$. Fine sand content decreased along the grazing pressure gradient, whereas medium 
sand content generally increased in both fixed and semi-fixed dunes. Organic matter and total $\mathrm{N}$ contents in $S_{1}$ were significantly higher than in $S_{2}$ and $S_{3}$, but no significant differences were observed between $\mathrm{S}_{2}$ and $\mathrm{S}_{3}$. The BSC in the semi-fixed dunes was more sensitive to grazing disturbance.

\section{Acknowledgements}

Funding was provided by the National Key Technology R\&D Program (2012BAD16B01), the Special Research Program for Public-welfare Forestry of China (201104077) and the National Natural Science Foundation of China (31170667). We thank the anonymous reviewers whose comments have greatly improved the manuscript.

\section{References}

Belnap J, Phillips S L, Miller M E. 2004. Response of desert biological soil crusts to alterations in precipitation frequency. Oecologia, 141: 306-316.

Büdel B, Darienko T, Deutschewitz K, et al. 2009. Southern African biological soil crusts are ubiquitous and highly diverse in drylands, being restricted by rainfall frequency. Microbial Ecology, 57: 229-247.

Chen R Y, Zhang Y M, Li Y, et al. 2009. The variation of morphological features and mineralogical components of biological soil crusts in the Gurbantunggut Desert of Northwestern China. Environmental Geology, 57: 1135-1143.

Cheng X L, An S Q, Liu S R, et al. 2004. Micro-scale spatial heterogeneity and the loss of carbon, nitrogen and phosphorus in degraded grassland in Ordos Plateau, northwestern China. Plant and Soil, 259: 29-37.

Cooper E J, Smith F M, Wookey P A. 2001. Increased rainfall ameliorates the negative effect of trampling on the growth of High Arctic forage lichens. Symbiosis, 31: 153-171.

Eldridge D J, Greene R S B. 1994. Microbiotic soil crusts: a view of their roles in soil and ecological processes in the rangelands of Australia. Australian Journal of Soil Research, 32: 389-415.

Eldridge D J, Koen T B. 1998. Cover and floristics of microphytic soil crusts in relation to indices of landscape health. Plant Ecology, 137: 101-114.

Guo Y R, Zhao H L, Zuo X A, et al. 2008. Biological soil crusts development and its topsoil properties in the process of dune stabilization, Inner Mongolia, China. Environmental Geology, 54: 653-662.

Han J C, Xie J C, Zhang Y, 2012. Potential role of feldspathic sandstone as a natural water retaining agent in $\mathrm{Mu}$ Us Sandy Land, Northwest China. Chinese Geographical Science, 22(5): 550-555.

Hiernaux P, Bielders C L, Valentin C, et al. 1999. Effects of livestock grazing on physical and chemical properties of sandy soils in Sahelian rangelands. Journal of Arid Environments, 41: 231-245.

Hu C X, Liu Y D, Song L R, et al. 2002. Effect of desert soil algae on the stabilization of fine sands. Journal of Applied Phycology, 14: 281-292.

Jiao W J, Zhu Q K, Zhang Y Q, et al. 2008. Factors affecting distribution of microbiotic crusts in the grain-for-green land of the loess region, northern Shaanxi, China. Frontiers of Forestry in China, 3: 165-170.

Kobayashi T, Liao R T, Li S Q. 1995. Ecophysiological behavior of Artemisia ordosica on the process of sand dune fixation. Ecological Research, 10: 339-349.

Lan S B, Wu L, Zhang D L, et al. 2012. Successional stages of biological soil crusts and their microstructure variability in Shapotou region (China). Environmental Earth Sciences, 65: 77-88.

Li S L, Werger M J A, Zuidema P A, et al. 2010a. Seedlings of the semi-shrub Artemisia ordosica are resistant to moderate wind denudation and sand burial in Mu Us sandland, China. Trees, 24: 515-521.

Li S L, Zuidema P A, Yu F H, et al. 2010b. Effects of denudation and burial on growth and reproduction of Artemisia ordosica in Mu Us sandland. Ecological Research, 25: 655-661.

Li X R, Kong D S, Tan H J, et al. 2007. Changes in soil and vegetation following stabilization of dunes in the southeastern fringe of the Tengger Desert, China. Plant and Soil, 300: 221-231.

Li X R, Tian F, Jia R L, et al. 2010. Do biological soil crusts determine vegetation changes in sandy deserts? Implications for managing artificial vegetation. Hydrological Processes, 24: 3621-3630.

Maestre F T, Cortina J. 2002. Spatial patterns of surface soil properties and vegetation in a Mediterranean semi-arid steppe. Plant and Soil, 241: $279-291$.

Maqubela M P, Mnkeni P N S, Issa O M, et al. 2009. Nostoc cyanobacterial inoculation in South African agricultural soil enhances soil structure, fertility, and maize growth. Plant and Soil, 315: 79-92.

O’Bryan K E, Prober S M, Lunt I D, et al. 2009. Frequent fire promotes diversity and cover of biological soil crusts in a derived temperate grassland. Oecologia, 159: 827-838.

Ponzetti J M, McCune B P. 2001. Biotic soil crusts of Oregon's shrub steppe: community composition in relation to soil chemistry, climate, and livestock activity. The Bryologist, 104: 212-225.

Rai H, Upreti D K, Gupta R K. 2012. Diversity and distribution of terricolous lichens as indicator of habitat heterogeneity and grazing induced trampling in a temperate-alpine shrub and meadow. Biodiversity and Conservation, 21: 97-113.

Read C F, Duncan D H, Vesk P A, et al. 2008. Biological soil crusts distribution is related to patterns of fragmentation and land use in a dryland agricultural landscape of southern Australia. Landscape Ecology, 23: 1093-1105.

Root H T, McCune B. 2012. Surveying for biotic soil crust lichens of shrub steppe habitats in the Columbia Basin. North American Fungi, 7: $1-21$.

Sanmanee N, Suwannaoin P. 2009. Investigation of organic carbon 
using rapid dichromate oxidation in comparison with dry combustion techniques among three groups of two different sizes of soils. Environment Asia, 2: 11-14.

Wang X Q, Zhang Y M, Jiang J, et al. 2009. Effects of spring-summer grazing on longitudinal dune surface in southern Gurbantunggut Desert. Journal of Geographical Sciences, 19: 299-308.

Wu B, Ci L J. 2002. Landscape change and desertification development in the $\mathrm{Mu}$ Us sandland, Northern China. Journal of Arid Environments, 50: 429-444.

Wu Y S, Hasi E, Wugetemole, et al. 2012. Characteristics of surface runoff in a sandy area in southern $\mathrm{Mu}$ Us sandy land. Chinese Science Bulletin, 57: 270-275.

Xiong H Q, Duan J Y, Wang Y, et al. 2011. Effects of biological soil crust on water infiltration and redistribution in the $\mathrm{Mu}$ Us sandland, Inner Mongolia, Northern China. Research of Soil and Water Conservation, 18(4): 82-87.
Xu J, Ning Y Y. 2010. Impact of overgrazing and enclosing on biomass and soil factors of the microbiotic soil crust in Horqin Sandy Land. Journal of Desert Research, 30(4): 824-830.

Yang Y S, Bu C F, Gao G X. 2012. Effect of biological soil crust on soil temperature in the Mu Us Sand Land. Arid Zone Research, 29(2): 352-359.

Zhang J H, Wu B, Jia Z Y, et al. 2010. Pattern of biological soil crust and its driving factors under Artemisia ordosica in Mu Us Sandy Land. Forest Research, 23(6): 866-871.

Zhang J H, Wu B, Lei Y K, et al. 2011. Analysis of Artemisia ordosica plant morphology and structure characteristics in $\mathrm{Mu}$ Us Sandland. Journal of Southwest Forestry University, 31(5): 6-9.

Zheng Y R, Rimmington G M, Xie Z X, et al. 2008. Responses to air temperature and soil moisture of growth of four dominant species on sand dunes of central Inner Mongolia. Journal of Plant Research, 121: 473-482. 